\title{
Trabajo productivo y trabajo improductivo
}

Tomás Rodríguez

Este trabajo pretende estudiar los conceptos de trabajo productivo y trabajo improductivo por Marx desarrollado en los escritos: Teorias de la Plusvalía, Los Grundrisse y el Capítulo VI (Inédito) de El capital.

Creemos que es importante estudiar estos conceptos debido a que en los últimos veinte años se ha venido desarrollando debates sobre los mismos con distintas motivaciones, por ejemplo en el campo del análisis sociológico y político, estos conceptos se quieren emplear para definir a las clases sociales y su papel dentro de la sociedad y la historia, tal es el caso de que algunos autores identifican a los trabajadores productivos con la totalidad de la clase trabajadora ${ }^{1}$, siendo una posición errónea debido al mismo tratamiento del concepto de trabajo productivo. Otros se interesan por estos conceptos desde análisis más económicos para poder explicar la importancia que van cobrando en el capitalismo moderno los trabajadores del sector servicios que tradicionalmente se consideran improductivos ${ }^{2}$, pero también por un manejo erróneo de los conceptos. $Y$ en el submundo capitalista se presenta la necesidad de estudiar estos conceptos en el marco de la existencia y persistencia de formas no capitalistas de producción para llegar a comprender su papel al interior de la formación social. ${ }^{3}$

Por lo anterior es importante abordar estos conceptos exponiendo su origen y el papel explicativo que juegan al interior de la crítica a la economía política que realiza Marx. Para ello en la primera parte se presenta el origen del concepto en Adam Smith y la crítica que presenta Mark sobre todo a su segunda definición de trabajo productivo. Luego presentamos la polémica que se desarrolla en torno al concepto para ver las objeciones existentes. Al final de esta primera parte pre- 
sentamos el concepto tal como aparece en los Grundrisse y en el VI Inédito.

En la segunda parte, presentamos el concepto de trabajo improductivo según las distintas formulaciones de los escritos de Marx mencionado.

En la tercera parte se quiere hacer una síntesis de lo expuesto anteriormente $y$ un intento de mostrar algunas relaciones existentes entre ambos conceptos.

\section{Concepto de trabajo productivo}

En esta primera parte trataré de presentar el concepto de trabajo productivo que aparece en distintos textos escritos por Marx, en concreto en "Teorias de la Plusvalia", los "Grundrisse" y el "Capítulo VI, (Inédito) Libro I de El Capital".

En la "Teoria de la Plusvalía" en la parte destinada a estudiar a Adam Smith en el apartado cinco, encontramos que Marx aborda el problema del trabajo productivo y el trabajo improductivo. Marx expone el concepto que Adams Smith plantea de trabajo productivo y dice que se trata de dos conceptos y no de uno, lo que origina incoherencias y contradicciones en el pensamiento de Smith. El primer concepto define el trabajo productivo en cuanto productor de capitaly el segundo en cuanto productor de mercancias. Marx como veremos retoma para sí el primero, la definición de trabajo productivo en cuanto productor de capital y defiende a Adam Smith de las críticas de otros autores mostrando en cada caso el orígen de su error. Al final del capítulo se encuentra un apéndice donde Marx expone su propio concepto de trabajo productivo. Pasemos ahora a mostrar lo dicho anteriormente.

Marx sostiene que el trabajo productivo es aquel trabajo asalariado que produce capital:

Trabajo productivo, desde el punto de vista dela producción capitalista, es el trabajo asalariado que, al cambiarse por la parte variable del capital, además de reproducir esta parte del capital (o sea el valor de su propia fuerza de trabajo) produce plusvalia para el capitalista"4

Marx dice que el trabajo productivo hay que verlo como una expresión de una condición social de producción. Si la finalidad del capitalismo es la acumulación de capital, productivo será aquel trabajo que cree plusvalia para posibitar esa acumulación, esa es la lógica imperante para definir la productividad y el trabajo productvo y dirá Marx: 
"La productividad del trabajo bajo el capitalismo se basa en la productividad relativa: el obrero, además de reponer el vlaor anterior, crea un valor nuevo. Su producto encierra más tiempo de trabajo que aquel que le mantiene y le sustenta como tal obrero. Este tipo de trabajo asalariado productivo es el que sirve de base a la existencia del capital"5

Esta concepción de trabajo productivo la retoma Marx de Adam Smith, de su primera teoría que Marx califica de exacta y le cita en la "Teorías de la Plusvalia, tomándolo de capitulo 3 del libro II de la" "Riqueza de las Naciones" donde Adam Smith dice:

"Existe una especie de trabajo que ańade algo al valor de la materia sobre que se ejercita, y otra que no produce aquel efecto. El primero, como que da nuevo valor a la cosa, puede llamarse con propiedad trabajo productivo; el segundo, por la razón contraria, no productivo. Asi, el trabajo de un artesano, en una manufactura, añade algún valor a los materiales en que trabaja, tales como su propio mantenimeinto y las ganancias del maestro."

Pero ésta es la primera concepción o teoría de Adam Smith sobre el trabajo productivo, pero presenta una segunda a la que se opone Marx y crítica. Esta segunda concepción ve al trabajo productivo en cuanto productor de mercancias, el trabajo productivo seria el de aquellos obreros que producen más mercancias de las que consumen ${ }^{8}$. Pero Marx dice que con esta segunda concepción Adam Smith vuelve a la postura de los fisiócratas que consideran como único trabajo productivo el trabajo agrícola, como el único que arroja plusvalía o un producto neto, al ver que estos sólo consumen una parte del producto agricola para su sustento y el resto sería un plusvalor producido con el que pagan la renta al terrateniente.

Este segundo concepto de trabajo productivo creo que puede ser rescatable siempre y cuando se vea la producción de mercancías como un medio para reproducir el capital. No se trata de producir mercancias para con ello obtener otras mercancias, como un sistema mercantil simple, de esquema M-D-M si no más bien producir mercancias para reproducir el capital, en un modo de producción capitalista, con el esquema D-M-D'. En este sentido sólo subordinado este segundo concepto al primero puede considerarse correcto este planteamiento de Adam Smith que Marx critica.

Marx dice que la base del error de Adam Smith es que no considera en su segundo planteamiento en dónde y cómo se origina la plusvalia:

"Si A. Smith, con pleno dominio del problema, se hubiese atenido a su 
análisis de la plusvalia creada por el cambio de capital, por salario, sólo habria reconocido como trabajo productivo el trabajo que se cambia por capital. La renta no puede cambiarse por trabajo productivo más que después de haberse convertido en capital"."

Como he dicho Maxx asume la primera concepción de Adam S Mith y defiende esta ante la critica de otros economistas. Marx agrupa en tres clases de motivaciones que mueven a esos ataques:

a) La negativa de las clases que se apoderan de la mayor parte de la riqueza de considerarse trabajadores improductivos.

b) Los defensores del capitalismo que sólo consideran como productivo a las actividades relacionadas con el capital industrial, dejando por fuera otras actividades o ramas donde hay trabajo productivo.

c) En la medida que hay una hegemonia del capital introduciéndose en las distintas ramas productivas, se quiere presentar como trabajo productivo a ciertas actividades relacionadas de alguna forma con el capital, aunque no produzcan plusvalía.

Vemos ahora cuáles son las concepciones de algunos de estos autores y la résplica dada por Marx.

- Garnier, considera como trabajo productivo todo aquel trabajo que produce mercancias, es decir que tiene valor de uso y un valor de cambio. Como hemos señalado antes no sólo se trata de producir mercancías, sino de producir un plusvalor, producir capital, mediante la oposición fuerza de trabajo-capital.

Garnier también considera como productivos los trabajos de aquellos que producen alguna cosa material para el Estado, como la reparación de puentes y caminos. A este planteamiento Marx no responde con un argumento, sólo se mofa de la idea con ironía ${ }^{10}$. Supongo que Marx considera este tipo de trabajos como simpie producción de valores de uso.

El tercer planteamiento de Garnier sólo considera como trabajos productivos aquellos que se materializan en un objeto, argumentando que es lo moralmente justo. Marx dice que no se trata de hacer un análisis en categorias morales y no dice más. Pero se puede argumentar que hay trabajos productivos que no se materializan en objetos, pero si producen plusvalia al capitalista que compra fuerza de trabajo para que ésta venda servicios como mercancias.

El último planteamiento de Garnier es el de considerar como productivo el trabajo de aquellos que producen medios de producción. Marx dice que esto es un absurdo, que no se puede considerar como 
productivo un trabajo por el consumo que se haga del objeto que produce.

Otro autor que se opone a la definición adoptada por Marx es Ganilh, quien plantea que trabajo productivo es aquel que produce mercancias como "valores de cambio" pues cree que las mercancias se valorizan en el intercambio y no en la producción. Esto hace que Max se remonte a explicar que el cambio no crea valor sino les da a los productos la forma de valor o la forma de mercancías ${ }^{11}$ y dice que lo único cierto es que la mercancía necesita entrar al intercambio para realizarse:

Lo único que hay de cierto en este razonamiento es que la mercancia debe entrar en el cambio como valor cambiable, pero la realización de su valor de cambio es el resultado del cambio mismo. Así es como se opera la conversión de la mercancia en dinero. ${ }^{12}$

Otro autor que aborda Marx es a David Ricardo, que no plantea diferencias en la concepción de trabajo productivo, considerando como tal aquel trabajo asalariado que produce una renta neta o plusvalor. Pero que diverge con Adam Smith al concebir el futuro del proletario, como le vemos en la siguiente cita:

"Ricardo comparte por entero la distinción establecida por A. Smith entre el trabajo productivo y el trabajo improductivo, en cuanto que cambia directamente su trabajo, el primero por capital y el segundo por renta, lo que no comparte son la ternura ni las ilusiones de $\mathrm{A}$. Smith acerca de los obreros productivos. El ser obrero productivo no es ninguna suerte. Obrero productivo es aquel que produce riqueza para otros. Si su existencia tiene alguna razón de ser, es precisamente bajo esta condición. Por tanto, desde el momento en que sea posible producir la misma cantidad de riqueza ajena con menos obreros productivos, no hay razón para no reducir el número de estos obreros"

Lo que sefiala Marx a Ricardo es que no logra responder a la antinomia inherente al desarrollo del capitalismo que por un lado tiene que reducir al mínimo el tiempo de trabajo necesario por lo que introduce la maquinaria, reduciendo la relación entre la masa del producto y la población productiva. Y por otro lado, tiene que apropiarse de la mayor cantidad de trabajo posible para acumular capital.

Luego nos encontramos con Ferrier, que considera el trabajo de los funcionarios públicos en cuanto que dirigen la producción, dice que un pais se puede enriquecer gracias a la buena administración pública. Marx responde que no es trabajo productivo el hecho de poner en movimiento el trabajo productivo de otros. 
Lauderdale y J.B. Say consideran como trabajo productivo el trabajo de todos aquellos que realizan algún tipo de servicio que no se materializan en un objeto. Con la diferencia de que Say considera que deben ser menor en número de aquellos que producen mercancías materiales. Marx tampoco argumenta con ellos y sólo los ironiza. Pues los servicios sólo son trabajo productivo cuando son realizados por un asalariado creando una plusvalia para el capitalista que ha comprado su fuerza de trabajo.

Destutt de Tracy plantea que trabajo productivo es aquel que produce valores de uso y por otro lado que la ganancia del capitalista se obtiene en el intercambio vendiendo más caro. No creo que sea necesario explicar porque Marx no lo considera trabajo productivo, púes se ha tratado anteriormente.

Por último hay una serie de autores que quieren justificar como trabajo productivo actividades de servicio, sobre todo el trabajo intelectual, argumentando que son trabajos útiles, que son producto de la división del trabajo, que el consumo de éstos es acicate para la producción material $y$ otros.

Marx argumenta que este tipo de trabajos no son productivos por diversas razones. Primero, porque no son asalariados, perciben rentas como producto de una distribución social de la plusvalía, segundo, que no producen mercancías aunque aparezca que están ayudando a reproducir la fuerza de trabajo como mercancia, pero en realidad es muy poco to que los obreros persiven para poder obtener este tipo de servicios y que cada vez es menor la preocupación del capitalista por capacitar a la mano de obra pués las actividades industriales se van simplificando por el uso de la máquina, lo mismo que la atención médica es menor. (Aqui hay que tomar en cuenta la época en que Marx está escribiendo). Tercero, al no vender su fuerza de trabajo por un salario $y$ no producir ninguna mercancia, tampoco producen plusvalía.

Como vemos Marx retoma el primer concepto de Adam Smith de trabajo productivo y el recorrido de los diferentes autores nos ha servido para ver las argumentaciones que hay en contra de este concepto. Ahora veremos como se ratifica este concepto en otros escritos de Marx, aunque sea superficialmente veremos como expresa este concepto en los Grundrisse y el VI Inédito.

En el tomo I de los Grundrisse, en las partes "Capital y trabajo", "Intercambio entre capital y trabajo" y el "proceso de valorización" Marx aborda el tema de trabajo productivo y trabajo improductivo. Básicamente se trata de presentar la oposición existente entre capital y trabajo, y la relación dialéctica existente entre ellos, en el cual el capital deviene 
en su contrario el trabajo para aparecer nuevamente pero acrecentado con un plusvalor. Ese es el movimiento del capitlal que nos vuelve a recordar la simple formula $D$ - M - D', tomando en cuenta que el trabajo surge del uso de la mercancía fuerza de trabajo.

Sólo en esta relación se puede hablar de trabajo productivo en el modo de producción capitalista:

"La transformación del trabajo (como actividad viva y orientada a un fin) en capital es en si el resultado del intercambio entre capital y trabajo en la medida en que este intercambio otorga al capitalista el derecho de propiedad sobre el producto del trabajo (y la dirección sobre el trabajo)... El trabajo mismo sólo es productivo al incorporarse al capital, constituye el fundamento de la producción y el capitalista es, por ende, el dirigente de la producción". ${ }^{14}$

Como vemos sólo en la relación trabajo-capital, en donde este último sale valorizado, puede haber trabajo productivo en el capitalismo.

Marx sefiala aqui el origen del concepto, en Adam Smith, en una nota al pie de página.

"Del análisis de los diversos aspectos del capital mismo, tiene que desprenderse qué cosa es trabajo productivo o no, un punto en torno al cual se ha disputado hasta el cansancio desde que Adam smith hizo esta distinción. Trabajo productivo es únicamente aquel que produce capital"15

Marx, como vemos, asume el concepto elaborado por Adam Smith pero a partir de su propio análisis del modo de producción capitalista.

En esta relación trabajo-capital se ve expresada la oposición entre valor de uso y valor de cambio que se ven sintetizadas en la mercancia, al presentarse el trabajo como valor de uso y el capital como valor de cambio $^{16}$. Insistiendo nuevamente sólo en esta relación existe el trabajo productivo en el capitalismo. Marx define al trabajador productivo de la siguiente manera:

"la verdadera definición de trabajador productivo consiste en lo siguiente: un hombre que no necesita ni exige nada más que lo estrictamente necesario para estar en condiciones de procurar a su capitalista el mayor beneficio posible"17

Como vemos Marx aqui conserva la misma definición de trabajo productivo expresada en la Teorias de la Plusvalia.

En el VI Inédito Marx vuelve sobre el concepto de trabajo productivo y dice: "es productivo el trabajo que genera directamente plusvalia, esto es, que valoriza el capital." ${ }^{\text {18 }}$ 
Marx apunta aquí que la fueza de trabajo debe incorporarse como la parte variable del capital para que pueda ser trabajo productivo; como trabajo vivo para conservar el valor del capital constante y producir más valor del que se consume para la reproducción de la misma fuerza de trabajo.

Un elemento que aparece aquí es que por la subsunción real del trabajo en el capital, se considera como agente real de proceso laboral al obrero colectivo y no al individual y es éste obrero colectivo el que crea la plusvalia, pero entran en este conjunto aquellos obreros individuales que estan subordinados al capital, es decir que necesitan vender su fuerza de trabajo para reproducirse y son explotados por el capital, entrando aquí no sólo el obrero manual, sino los técnicos, los ingenieros, etc, que al vender su fuerza de trabajo y ponerla en uso en el proceso de producción están valorizando el capital.

Como vemos en los tres escritos se conserva el mismo concepto de trabajo productivo aunque se relacionan con distintos aspectos del análisis del modo de producción capitalista.

\section{Concepto de Trabajo Improductivo}

En esta segunda parte expondre el concepto de trabajo improductivo utilizado por Marx, como es presentado en las tres obrar sefialadas.

El trabajo improductivo puede ser conceptualizado de manera atirmativa o como negación del trabajo productivo. A excepción de algunas definiciones en la Teorias de la Plusvalia tiende a predominar en Marx la definición como negación del trabajo productivo.

En la Teorias de la plusvalia se presentan también dos definiciones de trabajo improductivo según el planteamiento de Adam Smith. La Primera definición es del tipo afirmativo y dice que trabajo improductivo es el que se cambia por renta o interés. No significa que el que realiza el trabajo improductivo persiva una renta, puede estar recibiendo un salario, sino que el origen de ese salario es la renta del capitalista, la parte de la plusvalía destinada al consumo por el capitalista. El trabajo improductivo es intercambiado por la renta del capitalista y por ello no produce plusvalía.

Esta definición de tipo afirmativo limita el trabajo improductivo a la esfera de la circulación dejando de fuera los trabajos que producen valores de uso no destinados al intercambio, es decir deja de fuera a los trabajos que no producen mercancias. Esta es quizá la razón por la que predomina la definición del concepto en negativo, es decir ver el trabajo improductivo como aquel que no se enfrenta con el capital valorizándolo. 
Aunque Marx se detiene más en explicar porqué estos trabajos que producen mercancias no todos son productivos.

La segunda definición de Adam Smith de trabajo improductivo, que como ha señalado Marx es errada, lleva a error también en la conceptualización del trabajo improductivo, Marx expresa esta segunda idea de trabajo improductivo de Adam Smith de la siguiente forma:

"El trabajo del obrero improductivo 'no produce valor; lo que se gasta en mantener a un servidor doméstico no se repone nunca; su trabajo no toma cuerpo ni se realiza en un objeto determinado o en una mercancia susceptible de ser vendida'. Por ejemplo 'sus servicios, por lo general, desaparecen en el preciso momento en que se prestan y rara vez dejan tras de si una huella o un valor mediante el cual puede obtenerse más tarde una cantidad igual de servicios". ${ }^{19}$

Marx argumenta que hay trabajos que se materializan en una mercancía y no por ello son trabajos productivos sino improductivos y que hay servicios o trabajos que no se materializan en un objeto y son productivos, como lo explica a continuación:

"...lo que clasifica a un trabajo como productivo o improductivo no es forzosamente el carácter especial del trabajo ni la forma de su producto. Un mismo trabajo puede ser productivo, si lo compra un capitalista, un productor, para obtener de él una ganancia, o improductivo, si lo compra un consumidor, una persona que invierte en él una parte de sus rentas para consumir su valor de uso, lo mismo si éste desaparece al ponerse en funciones la fuerza de trabajo, que si toma cuerpo o se realiza en un objeto". 20

Adam Smith plantea también esta segunda definición de trabajo improductivo en una postura similar a los defensores del sistema monetario, dice que trabajo improductivo es el que no se convierte nuevamente en dinero. Pero hay que considerar que el dinero en sí no es capital.

Para Marx el trabajo improductivo crea directamente valores de uso para el consumidor. Se adquiere el producto del trabajo improductivo por su propio valor de uso, no para crear valor, se adquiere para el consumo, por lo tanto en una relación de intercambio no se repone lo gastado por parte del comprador, en este sentido no es suceptible de repetición con el mismo fondo con que se ha comprado como sucede con el trabajo productivo que repone la cantidad de capital con la que se ha comprado ese trabajo.

Es claro para Marx que el trabajo que no produce plusvalia es un trabajo improductivo aunque este sea incluso contratado por el ca- 
pitalista para producir mercancias que contengan un plusvalor como se ve en la siguiente cita:

"El obrero que no reponga al cabo del año más que el equivalente de su salario, no es productivo para el capitalista, pués sólo reembolsa a éste el salario, o sea el precio por el que compra su trabajo". ${ }^{21}$

Por eso creo que la definición de trabajo improductivo como negación de lo que es el trabajo productivo es más adecuada en tanto permite más flexibillidad y poder comprender casos como el anterior, $Y$ esto es claro si sólo tenemos dos conceptos para dividir el trabajo en base a la productividad, si un concepto es restringido como es el caso del de trabajo productivo, el otro debe ser flexible para poder comprender a todos los que el primero deja fuera y esto sólo es posible expresando al segundo como negación del primero. Si los dos fueran restringidos dejarian muchas actividades sin ser clasificadas.

En los Grundrisse aparece el concepto de trabajo improductivo en la forma de negación de lo que es el trabajo productivo como lo podemos ver en la siguiente cita:

“...sólo es productivo el trabajo que produce capital, y por tanto que el trabajo que no lo hace, por útil que pueda ser —del mismo modo puede ser danino- no es productivo para la capitalización, hence (por tanto) es trabajo improductivo". ${ }^{22}$

A Marx en los Grundrisse le interesa sef́alar que todo trabajo que no se enfrenta al capital para valorizarlo es improductivo dentro del capitalismo. Es decir que todo trabajo que no entra en el devenir del capital como señale en la primera parte, es decir dentro de la circulación de capital, no es trabajo productivo. Los trabajos improductivos entran en la circulación simple de mercancías.

“... el trabajo, pues, en su existencia inmediata, separado del capital, no es productivo. Como actividad del obrero nunca llega a ser productivo, tampoco, ya que el trabajo únicamente entra en el proceso simple de la circulación". ${ }^{23}$

En la relación que se establece al intercambiar el producto del trabajo improductivo, ninguno de los contratantes se presenta como capitalista. Ninguno representa el capital, no hay una relación de trabajo-capital, sino un simple intercambio de mercancias.

En el VI Inédito se mantiene el mismo concepto de trabajo improductivo, es decir aquel trabajo que no valoriza al capital, pero se enfoca desde otra perpectiva, pero para señalar los mismos aspectos. Aquí se dice que el trabajo improductivo se consume a causa de su 
valor de uso, no es un consumo productivo que conserve el valor del capital constante y cree un plusvalor, es un trabajo improductivo. El trabajo improductivo entra en la circulación simple de mercanias M-D$M$ donde el dinero no tiene la función de capital, sino de medio de circulación.

En el VI Inédito se insiste en que por el desarrollo de la producción capitalista, los trabajadores improductivos tienden a ser asalariados, especialmente los servicios que se prestan directamente, y atendiando a todo lo dicho en el párrafo anterior Marx dice que "Todo trabajador productivo es un asalariado, pero no todo asalariado es un trabajador productivo"24 Hay otras dos consideraciones que llevan al error de ver como trabajos productivos a trabajos que son improductivos. La primera es que por el predominio de las relaciones capitalistas se da una subsunción imaginaria en los trabajadores independientes en donde ellos se consideran sus propios asalariados y sus propios medios de producción se les enfrentan en su imaginación como capital ${ }^{25}$ y por ello se tienden a ver como obreros productivos. El segundo es el de los funcionarios estatales que se consideran obreros productivos por ser asalariados y porque sus salarios provienen en parte de los impuestos indirectos que son agregados a los costos de la mercancia. Ni el trabajador independiente, ni el funcionario público son obreros productivos porque no se enfrentan con su trabajo al capita valorizándolo.

Tanto el trabajo productivo como el improductivo se definen no por el contenido concreto de su trabajo, que puede ser el mismo, sino por las determinaciones en las que se realizan, es decir la relación social que se establece al ejecutar el trabajo.

Para terminar esta parte abordaremos un texto en el cual Marx se sale de la línea en que ha venido tratando estos conceptos en el conjunto de los escritos que hemos utilizado para este trabajo. En el apéndice al apartado dedicado a Adam Smith en la Teorias de la plusvalia encuentro que Marx no incluye a ciertas actividades en ninguno de los dos conceptos:

"¿Y en qué caso se hallan los obreros o los agricultores que trabajan solos y no producen, por tanto, como capitalistas? Puede ocurrir como acontece siempre con el agricultor (aunque no es el caso del jardinero que trabaja a domicilio) que sean productores de mercancías, las cuales venden... aún produciendo mercancías, estos obreros no son productivos ni improductivos, pues su producción no entra dentro del marco del tipo de producción capitalista. ${ }^{26}$

Aqui hay que señalar que en la Teorías de la plusvalía es el único escrito en donde aparece el concepto de trabajo improductivo definido 
positivamente, como aquel trabajo que se intercambia por renta, es decir nos encontramos con dos conceptos estrechos que obligan a dejar por fuera algunas actividades, (aunque también se presenta en el mismo escrito la definición de trabajo improductivo como aquel que no es productivo, como le he mostrado anteriormente).

El agricultor puede ser tratado como el productor independiente, aplicándole el análisis que hace Marx para este último en el VI Inédito y que he señalado anteriormente.

Ateniendonos al conjunto de los escritos y aplicando en sentido estricto el concepto de trabajo productivo podemos decir que el agricultor individual, en tanto que no se enfrenta con el capital valorizándolo, realiza un trabajo improductivo.

Lo que si ilumina este texto es el carácter explicativo de estos conceptos al interior del funcionamiento del modo de producción capitalista y que es válido para el conjunto de los escritos, lo que permite decir que los conceptos de trabajo productivo y trabajo improductivo utilizados por Marx sólo pueden ser aplicados al modo de producción capitalista y expresan o sintetizan unas determinadas relaciones de producción, de tal manera que los trabajos que respondan a modos de producción, anteriores (o posteriores) no podrian ser incluidos en estas categorias.

Aqui el problema con que nos encontramos es que no nos enfrentamos en la realidad a modos de producción "puros" sino más bien con Formaciones Sociales, en las que subsisten y se relacionan distintas formas de producción bajo el dominio y la hegemonia de una de ellas, que para nuestro caso es la forma capitalista, lo que nos hace variar las condiciones del análisis a la hora de ver qué trabajo es productivo o no. Por ejemplo el caso anterior del agricultor independiente, realiza un trabajo productivo en una formación social del submundo capitalista de producción en tanto que reduce el costo de la reproducción de la fuerza de trabajo lo que permite la obtención de una plusvalía extraordinaria por parte del capitalista, nos encontramos ante una subsunción indirecta del trabajo en el capitap?. Pero hay que señalar que no sólo se trata de relaciones de explotación sino también de expoliación, es decir las relaciones sociales de producción de las que parte este análisis son distintas de las que parte el análisis de Marx ubicado en la Inglaterra del siglo XIX. 
Relación de los conceptos de trabajo productivo y trabajo improductivo.

En esta última parte voy a tratar de sintetizar lo expuesto e intentaré mostrar la relación entre ambos conceptos.

Del análisis anterior se deduce que sólo es productivo aquel trabajo que se convierte directamente en capital. El trabajo que se convierte en capital variable y produce plusvalía. Visto más detenidamente el trabajo vivo que se transforma en capital tiene que conservar el valor del capital constante, reponer el mismo valor que cuesta el mismo como fuerza de trabajo, es decir el capital variable y crear más valor, la plusvallia.

El dinero y las mercancías en el mismo proceso se convierten en capital, mejor dicho son convertidos en capital por la acción del obrero que ha perdido la propiedad de los objetos que produce, al ser propiedad del capitalista que ha comprado su fuerza de trabajo por su valor de uso.

Trabajo productivo es el que se cambia directamente por dinero considerado como capital. Es la oposición del trabajo al capital y viceversa, en donde el capital deviene en su contrario al trabajo para aparecer acrecentado, lo que refleja el trabajo productivo. En este intercambio hay que considerar dos elementos entrelazados ${ }^{28}$ :

a) Que la relación en un primer momento aparece como intercambio de equivalentes, en donde aparece el capital como dinero y el trabajo como mercancia, se cambia trabajo vivo por trabajo materializado.

b) La segunda fase no es de intercambio. El comprador de fuerza de trabajo actua como capitalista y consume la mercancía que ha comprado poniéndola a trabajar y se apropia del producto del trabajo. Pero como la cantidad de valor producida es mayor que la cantidad de valor que ha costado la fuerza de trabajo, entonces se convierte el dinero en capital, al apropiarse el capitalista de ese plusvalor y reinvertirlo..

De aquí que Marx pueda decir que trabajo productivo es aquel que se intercambia directamente por trabajo. Una mayor cantidad de trabajo vivo se intercambia por una cantidad menor de trabajo materializado. $Y$ ésta es una expresión sintética de la definición de que trabajo productivo es el que se intercambia directamente por capital ${ }^{29}$.

El resultado o mejor dicho, la finalidad del modo de producción capitalista no es producir valores de uso, ni siquiera mercancías, sino producir plusvalía para el capital, los primeros los produce en tanto son necesarios para esa finalidad. Por eso el carácter específico del trabajo productivo no se halla relacionado con el contenido concreto del trabajo. 
Lo que determina que un trabajo sea productivo o no, son las circunstancia, la relación o no con el capital y no su contenido, ya que ambos pueden tener el mismo contenido.

En el trabajo improductivo el dinero tiene la función de ser medio de pago, con el cual puedo adquirir valores de uso, es el valor de uso concreto el que se desea obtener, es un gasto hecho para el consumo y no para aumentar el capital. No basta que el trabajo se intercambie por dinero para que sea productivo. El trabajo improductivo entra en la circulación simple de mercancias y no en la circulación de capital.

Ambos trabajos, productivo e improductivo, no existen por separado, estan en relación : por ejemplo el salario o las retribuciones que reciben los obreros improductivos se originan en el plusvalor creado por los obreros productivos, es una parte de la plusvalia que se convierte en renta del capitalista y no en capital, también pueden ser adquiridos por el salario de los obreros productivos, pero en menor medida como lo señala Marx en la siguiente cita:

"Todos los trabajos improductivos tienen como caracteristica el que, al igual que las demás mercancías destinadas al consumo que puedo comprar, se hallan a mi disposición en la medida en que explote a obreros productivos. El obrero productivo es, por tanto, de toda la gente, el que menos puede disponer de los servicios de obreros improductivo, aunque sea el que más contribuye a pagar los servicios impuestos (el estado, las contribuciones). Y a la inversa, mi capacidad para emplear a obreros productivos, lejos de aumentar, disminuye en la proporción en que tengo a mi servicio obreros improductivos". ${ }^{30}$

Como vemos ambas realidades estan interrelacionadas y se influyen mutuamente. El aumento del consumo de servicios de trabajadores improductivos como sefiala Marx reduce la capacidad de comprar trabajo productivo.

\section{Conclusiones}

Primero, el concepto de trabajo productivo Manx lo retoma de la primera conceptualizacion de Adam Smith, pero desde su propio análisis del modo de Producción Capitalista.

Segundo, ambos conceptos en su sentido estricto sólo pueden ser aplicados al modo de producción capitalista y su finalidad es la de explicar la lógica del mismo en la relación trabajo-capital.

Tercero, es necesario ver este concepto de trabajo productivo y el de trabajo improductivo de manera particular en las distintas formas de extracción de plusvalía en el interior de las distintas formaciones sociales 
reales.

Cuarto, predomina en Marx una definición de trabajo improductivo como negación del trabajo productivo en los tres escritos estudiados, lo que le da amplitud y flexibilidad al concepto.

Quinto, ambos conceptos, así como las realidades que expresan estan estrechamente ligadas y sólo pueden ser comprendidas en esta relación.

\section{Notas.}

- Este trabajo incluye las observaciones y comentarios hechos por Joaquín Arríola y Aquiles Montoya a la redacción original, por lo que les estoy agradecido.

1. Fine, Ben y Harris, Laurence. Para releer "El capital". Fondo de Cultura Económica, México, 1985,pag.68-69

2) Ibid. pag 61

3. Montoya, Aquiles. Necesidad Teórica de la categoría subsunción indirecta. Realidad Económico-Social, UCA, San Salvador, Enero-Febrero 1988. pag. 57

4. Marx, Karl. Teorías de la Plusvalía. Tomo I Alberto Corazón editor. Madrid 1974.pag. 134

5. Smith, Adam. La Riqueza de las Naciones. Tomo II Universidad Autónoma de Centro América, Costa Rica, 1986 pag.65

6. Marx, Karl.Teorías de la Plusvalía.pág. 134

7. Ibid, pág. 136

8. Ibid, pág. 142

9. Ibid, pág. 150

10. Ibid, pág. 158

11. Ibid, pág. 164

12. Ibid. pág. 165

13 lbid. Pág. 177.

14. Marx, Karl. elementos Fundamentales para la crítica de la Economía Política (borrador) 1857 - 1858. Tomo I Siglo XXI, 2a. Edición, México, 1971. pág. 249.;

15. Ibid. pág. 245.

16. Ibid. pág. 235.

17. Ibid. pág. 215.

18. Marx, Karl. el capital, libro I, capitulo VI (Inédito) Siglo XXI, 7a. edición, México, 1979. pág. 78.

19. Marx, Kasrl. Teorias de la plusvalía, pág. 140.

20. Ibid. pág. 142.

21. Ibid. pág. 140.

22. Marx, Karl. elementos fundamentales. pág. 246.

23. Ibid. pág. 249.

24. Marx, Karl, VI Inédito. pág. 80. 
25. Ibid. pág. 82.

26. Marx, Karl. Teorías de la plusvalía. pág. 222.

27. Montoya, Aquiles. Op. cit. pág. 64-65.

28. Marx, Karl, Teorías de la Plusvalía, pág. 218.

29. Ibid. pág. 219.

30. Ibid. pág. 222.

Digitalizado por Biblioteca "P. Florentino Idoate, S.J." Universidad Centroamericana José Simeón Cañas 